\title{
Simulation and Analysis of Active Power Filter for Mitigation of Power Quality Problems in a Wind Based Distributed Generation
}

\author{
Irfan Ali Channa a, ${ }^{\text {a }}$, Mohsin Ali Koondhar ${ }^{\mathrm{b}}$, Naveed Mohsin Mughal ${ }^{\mathrm{b}}$, Muhammad Shahzad \\ Bajwa $^{\mathrm{b}}$, Syed Abid Ali Shah Bukhari ${ }^{\mathrm{c}}$, Muhammad Ismail Jamali ${ }^{\mathrm{b}}$ \\ ${ }^{a}$ Department of Automation, Beijing University of Chemical Technology, Beijing China \\ ${ }^{\mathrm{b}}$ Department of Electrical Engineering, Quaid-e-Awam University of Engineering, Science and \\ Technology Nawabshah \\ ${ }^{c}$ Department of Electrical Engineering, Quaid-e-Awam University College of Engineering, Science \\ and Technology Larkana \\ ${ }^{*}$ Corresponding Author: irfanali@mail.buct.edu.cn
}

\begin{abstract}
The adoption of natural energy sources has seen a phenomenal rise during recent decades. The reason is an improvement in their energy conversion capabilities, as well as simplification of their associated electronic control circuitry. The result at their use at a localized distributed generation level. This work is an attempt to understand and present the power quality impacts of wind and solar power generation at a localized system of distribution voltage level. The simulation is finalized in MATLAB/SIMULINK. Next a very popular solving these power quality problems namely, active power filter beside its shunt type is tested over the simulated model. Moreover, its control algorithm is implemented mathematically with $P-Q$ theory and the results are analyzed for better power quality improvement.
\end{abstract}

Keywords- Active Power filter, Current Harmonics, Local Power System, P-Q Theory, Wind Power

Date Received: 23-10-2020

Date Accepted: 23-02-2021

Date Published: 08-06-2021

\section{INTRODUCTION}

$\mathrm{N}$ OWADAYS active filtering of electric power becomes major technology for mitigation of harmonics in a singlephase power line generated by loads. Harmonic is to be defined as a requisite collective of the sustaining frequency introduced in electrical power that causes continuous distortion [1]. The major cause of harmonics is the use of nonlinear devices like the Uninterruptible Power Supply (UPS) system, and rectification system, etc. The current harmonics introduced in the circuit result to be the greater voltage distortion which results in an abnormal operation of switching devices, greater power loss \& temperature rise $[2,3]$. To reduce harmonics contents by employing active power filter control purposed to purify the performance $[4,5]$.

Historically passive filters are used to eject these current harmonics' but now a day's research is to be done on active power filters as correlated to the passive filters. It can be recognized as a better solution to cancel out the problem created by nonlinear loads [6,7]. Low voltage distribution systems composed of non-conventional energy systems such as wind energy systems; PV systems, small-scale hydro systems, etc. are discussed in $[8,9]$. These types of a distributed systems can be operated isolated or they may be interconnected to the medium voltage distribution network [10]. Its application is discussed [11] from the local side are that it provides reliability, reduces emission, also provides both thermal and electricity needs, improve power quality \& reduce the cost of energy. The microgrid can be used for varieties of loads with a single operating system such as power and heating loads in [12]. The microgrid advantages are discussed also in [13].

Their difference between microgrids \& the general energy resources are defined as such as the microgrid is installed normally near to the consumer load; they also have a smaller capacity as compared to the conventional grid [14-16]. The impact which occurs in distribution generation on power quality depends upon the factors such as type of distribution generation, its interference with power quality, the feeder voltage regulation practice $[17,18]$.

In this paper, a shunt active power filter with hysteresis control using clerk transformation is implemented to overcome harmonic distortion in a small scale wind power (DG)

The remaining parts of the manuscript are organized as follows: Section 2 describes the wind power distributed generation. Section 3 outlines and discusses exhaustively the power quality issues in distributed generation. Section 4 highlights the working principle of shunt active power filter. and its need. Section 5 describes the methodology, results, and discussions. Finally, conclusions are discussed in section 6 .

\section{A. POWER QUALITY ISSUES IN DISTRIBUTED GENERATION}

The contact which arises in distribution generation on power quality depends upon the factors such as type of distribution generation, its interference with power quality, the feeder voltage regulation practice. In this system wind turbines are used to produce electrical energy, the wind turbine is linked to the generator (mostly induction) by a multiple ratio gearbox. 
The kinetic energy of the wind rotates the rotor blades of the wind turbine and transfers this wind energy to the generator through the gearbox [18]. There are some positive as well as negative effects of power quality on distribution generations; the positive impacts are backup generation and on-site power supply. The negative impacts include voltage flicker, harmonics, voltage sags, sustained interruption, voltage regulation, etc [19].

\section{B. ACTIVE POWER FILTER AND ITS NEED}

Nowadays the introduction of nonlinear loads causes greater damage to the quality of electrical power. The change in the amplitude of the supply system and the boost up in the harmonics contents is the basic effect on the system [20]. Also, these power quality complications are seriously faced today by the industrial customer, especially in the micro gird which exploits local distributed generation units.

Anciently passive filters are used to defeat these current harmonics but now a day's research is to be done on active power filters as measured to the passive filters. For example, an active power filter (shunt) is used to overcome the harmonics current. This type of active power filter can be recognized as a better solution to defeat the problem created by nonlinear loads [21].

\section{a. ACTIVE POWER FILTERS AND ITS TYPES}

It is an electronic device worn to modify power quality problem's especially whereas voltage sag \& current, voltage harmonics as shown in figure 1 [22]. In nonlinear load conditions, Active filtering technology is widely used current, voltage harmonics dependent on time.

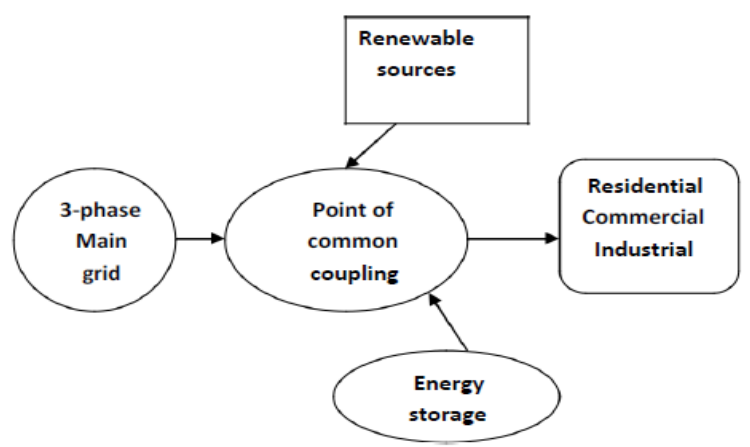

Fig. 1. Block diagram of local power system

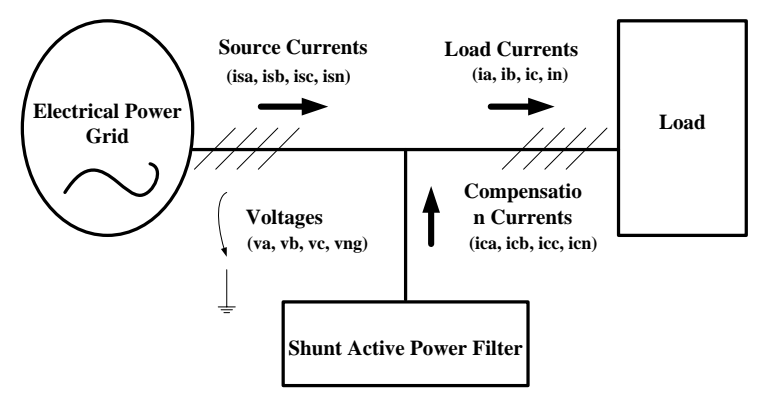

Fig. 2. Active Power Filter [1]

AF is used as a buffer between supply terminal voltages \& PWM voltage produced by active filter by connecting series- inductor at the input of voltage source Inverter Bridge [23-26]. Classifications of APF occupying on topology, types of converter \& on no: of phases, so converter based includes PWM with current, voltage fed PWM inverter bridge structure.

Further converter types are categorized by voltage source inverter and current source inverter. Whereas APF also is divided according to their cartography like Shunt, Series active $\&$ compound active power filters [27, 28]. Fig 2 shows the working principle of shunt active power filter in a wind-based distributed generation.

\section{PROPOSED METHODOLOGY}

The block diagram of the methodology is shown in figure 3 . This describes the simulation of the microgrid structure, design of the shunt active power filter with a localized power system. Afterward, the control strategy for such a system namely activereactive theory with hysteresis control technique is implemented over a system and the calculation of total harmonic distortion in each phase of a localized power system.

\begin{tabular}{|c|c|c|c|}
\hline $\begin{array}{c}\text { Local } \\
\text { Power } \\
\text { Syste } \\
\mathrm{m} \\
\text { Design }\end{array}$ & $\begin{array}{c}\text { Implement } \\
\text { Active } \\
\text { ation of P- } \\
\text { Filter } \\
\text { in Wind } \\
\text { Based DG }\end{array}$ & $\begin{array}{c}\text { Measuring of } \\
\% \text { THD of } \\
\text { harmonic contents } \\
\text { and power factor } \\
\text { improvement }\end{array}$ \\
\hline
\end{tabular}

Fig. 3 Layout of Research work

\section{A. ADOPTION OF P-Q THEORY IN SAPF IN LOCAL POWER SYSTEM WITH WIND-BASED DISTRIBUTED GENERATION}

Shunt active power filter is widely in practice and practice can be contrivances to overcome the problems of quality of the power system, also many active filters are employing an entire world. Gyugyi in 1976 first introduced the concept of active filtering technology. Figure 4 illustrates the fundamental concept afterward compensation of shunt current. Further, this displays the providing of power source to a nonlinear load of a source that is being compensated by SAPF.

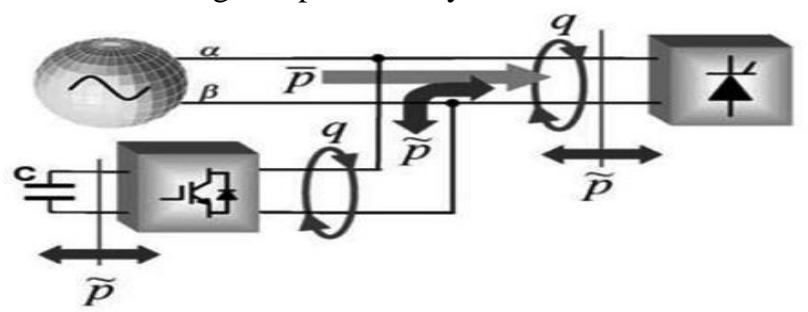

Fig. 4. Adoption of P-Q theory in SAPF in local power system

The controller of the filter found out the compensating reference current in real-time and the power converter source to symphonize compensating reference current with steep integrity. Here APF acts as a source of current control of a three-phase basis, which creates the harmonic current in opposite phase, angle i.e. 180 degrees depending on reference currents ica, icb, and icc. 


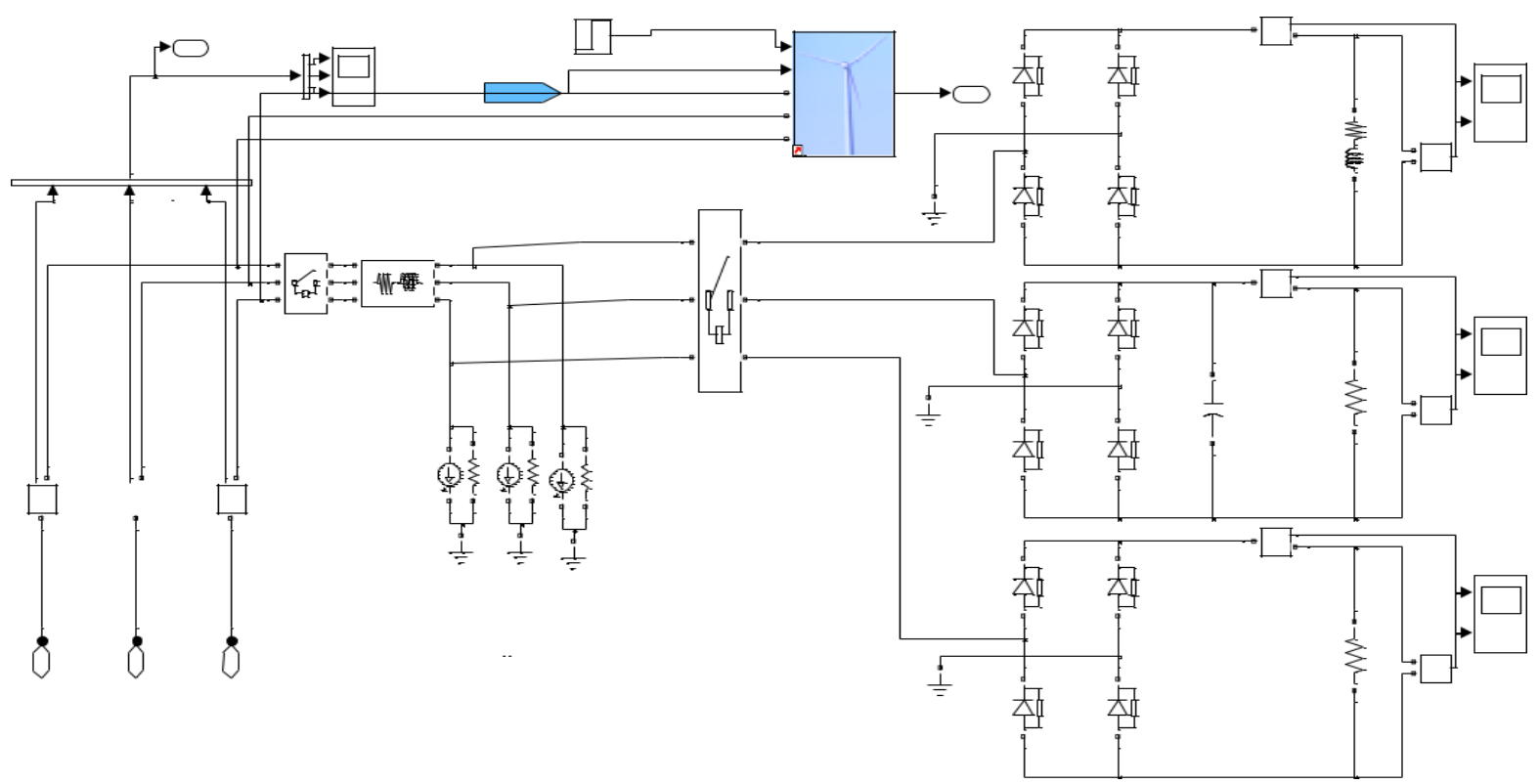

Fig. 5. Simulink Diagram of Non-linear Load with Wind Power based D.G

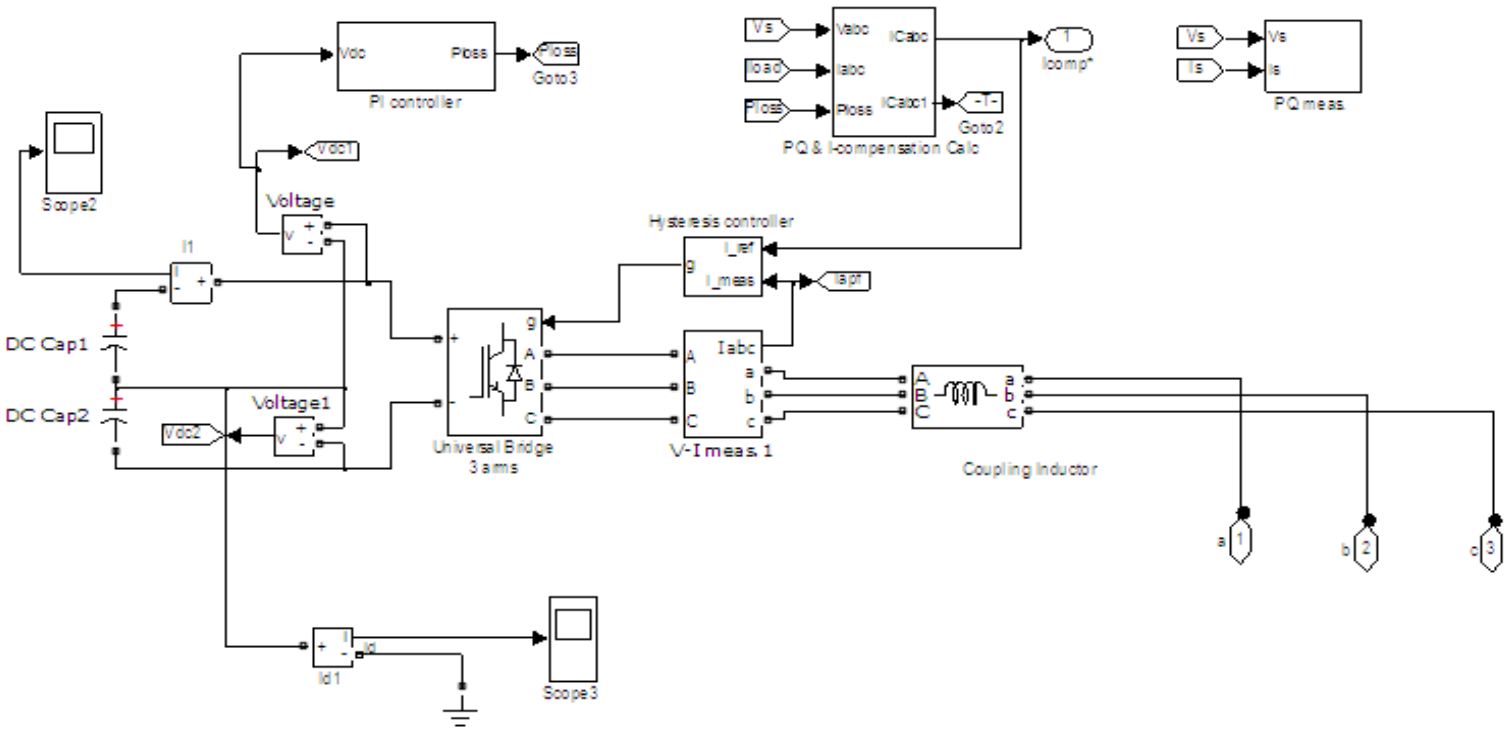

Fig. 6. Simulink diagram of Shunt APF

The real power (p) which is calculated from the load can be divide into two parts

(i) Average part (p)

(ii) Oscillating part (p )

Correspondingly the imaginary power (q) of the load can be divided into two parts:

(i) Average part (q)

(ii) Oscillating part (q ).
Then unwanted portions of the real and imaginary powers of the load should be compensated are preferred.

\section{B. OPERATION OF SHUNT ACTIVE POWER FILTER}

To obtain the signals for fast switching insulated gate bipolar transistor inverter, gain current signals sent to PWM converter as reference signals. Concluded interfacing inductor, these currents are inserted in the system near the load. The performance of shunt APF of individual of the system impedance as it matches the implanted currents with reference current signals and tries to decreases the disturbances shown in figure 6. 
Referring to general the following steps are required for the working principle of shunt active power filter to obtain reference harmonic currents of the active power filter.

1. Calculation of load currents $i \alpha, i \beta, i \gamma$ \& Source voltages $V \alpha, V \beta, V \gamma$

$$
\begin{aligned}
& {\left[\begin{array}{l}
i \alpha \\
i \beta \\
i o
\end{array}\right]=\left[\begin{array}{ccc}
\frac{1}{\sqrt{3}} & \frac{1}{\sqrt{3}} & \frac{1}{\sqrt{3}} \\
\sqrt{\frac{2}{3}} & -\frac{1}{\sqrt{6}} & -\frac{1}{\sqrt{6}} \\
0 & \frac{1}{\sqrt{2}} & -\frac{1}{\sqrt{2}}
\end{array}\right] \cdot\left[\begin{array}{c}
i a \\
i b \\
i c
\end{array}\right]} \\
& {\left[\begin{array}{l}
V \alpha \\
V \beta \\
V o
\end{array}\right]=\left[\begin{array}{ccc}
\sqrt{\frac{2}{3}} & -\frac{1}{\sqrt{6}} & -\frac{1}{\sqrt{6}} \\
0 & \frac{1}{\sqrt{2}} & \frac{1}{\sqrt{2}}
\end{array}\right] \cdot\left[\begin{array}{c}
V a \\
V b \\
V c
\end{array}\right]}
\end{aligned}
$$

2. Calculation of instantaneous real \& imaginary active, reactive power.

$$
\left[\begin{array}{l}
p \\
q
\end{array}\right]=\left[\begin{array}{cc}
V \alpha & V \beta \\
-V \beta & V \alpha
\end{array}\right] \cdot\left[\begin{array}{c}
i \alpha \\
i \beta
\end{array}\right]
$$

3. Calculation of reference currents from oscillatory part of a result obtained from the above step.

$\left[\begin{array}{l}i c_{1} \\ i c_{2}\end{array}\right]=\frac{1}{V \alpha^{2}+V \beta^{2}}\left[\begin{array}{cc}V \alpha & V \beta \\ V \beta & -V \alpha\end{array}\right] \cdot\left[\begin{array}{l}p \\ q\end{array}\right]$

$\left[\begin{array}{l}i c_{1} \\ i c_{2}\end{array}\right]=\frac{1}{V \alpha^{2}+V \beta^{2}}\left[\begin{array}{cc}V \alpha & V \beta \\ V \beta & -V \alpha\end{array}\right] \cdot\left[\begin{array}{l}p_{o s c} \\ q_{o s c}\end{array}\right]$

5. Finally, obtaining reference harmonic currents.

$$
\left[\begin{array}{l}
I c a \\
I c b \\
I c c
\end{array}\right]=\sqrt{\frac{2}{3}}\left[\begin{array}{ccc}
1 & 0 & \frac{1}{\sqrt{2}} \\
-\frac{1}{2} & \frac{\sqrt{3}}{2} & \frac{1}{\sqrt{2}} \\
-\frac{1}{2} & \frac{\sqrt{3}}{2} & \frac{1}{\sqrt{2}}
\end{array}\right] \cdot\left[\begin{array}{l}
I c 1 \\
I c 2 \\
I c 3
\end{array}\right] \text { (6) }
$$

\section{RESULTS AND DISCUSSIONS}

Results showing the load \& source voltages, currents of a 3$\varnothing$ power supply, shunt active power are coupled parallel with source and load (Nonlinear load \& distributed generation). The breaker of an active power filter is switched on for 0.8 seconds to 3.8 seconds. Results are showing to mitigate current harmonics. Specification of the simulated model has described as following:

Table 1 Local power system parameters with wind-based distributed generation using shunt active power filter

\begin{tabular}{|l|l|l|}
\hline S. No & Parameters & Values \\
\hline 1 & 3- phase Power Supply & 400 Volts \\
\hline 2 & Frequency & $50 \mathrm{~Hz}$ \\
\hline 3 & Breaker opening time & 0.8 to $3.8 \mathrm{sec}$ \\
\hline 4 & Coupling inductor & $2 \mathrm{mH}$ \\
\hline 5 & Wind Generator type & $\begin{array}{l}\text { Squirrel-cage } \\
\text { induction generator }\end{array}$ \\
\hline 6 & $\begin{array}{l}\text { Wind turbine output } \\
\text { power }\end{array}$ & $10 \mathrm{KW}$ \\
\hline 7 & Wind speed & $9 \mathrm{~m} / \mathrm{sec}$ \\
\hline 8 & DC-Link controller & P-I \\
\hline 9 & DC-Link Voltage & 680 volts \\
\hline 10 & Dc link Filter capacitance & 400 Micro Farad \\
\hline
\end{tabular}

The figures of supply voltage and load source current are given below
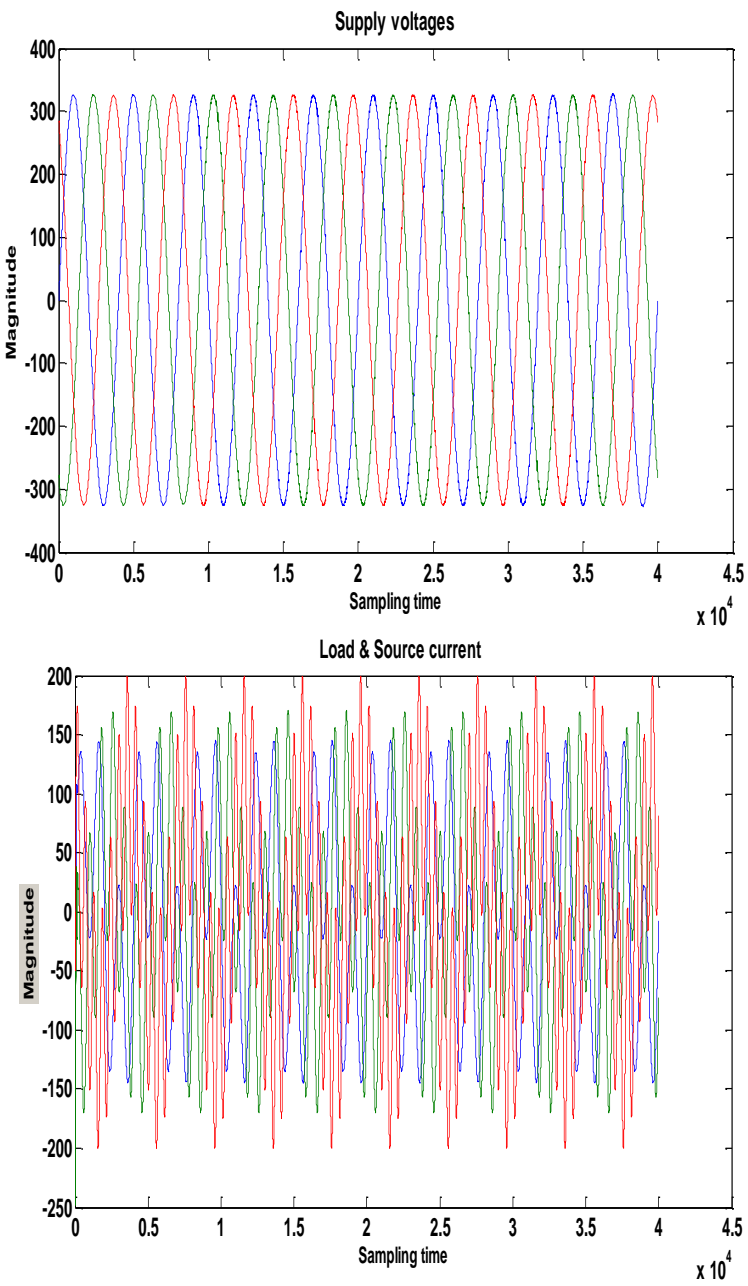

Fig. 7. Supply Voltage \& Load Current Source 
Also, the figures of instant active \& reactive power without

The waveform of considerable improvement in active \& filters are shown in figure 8.

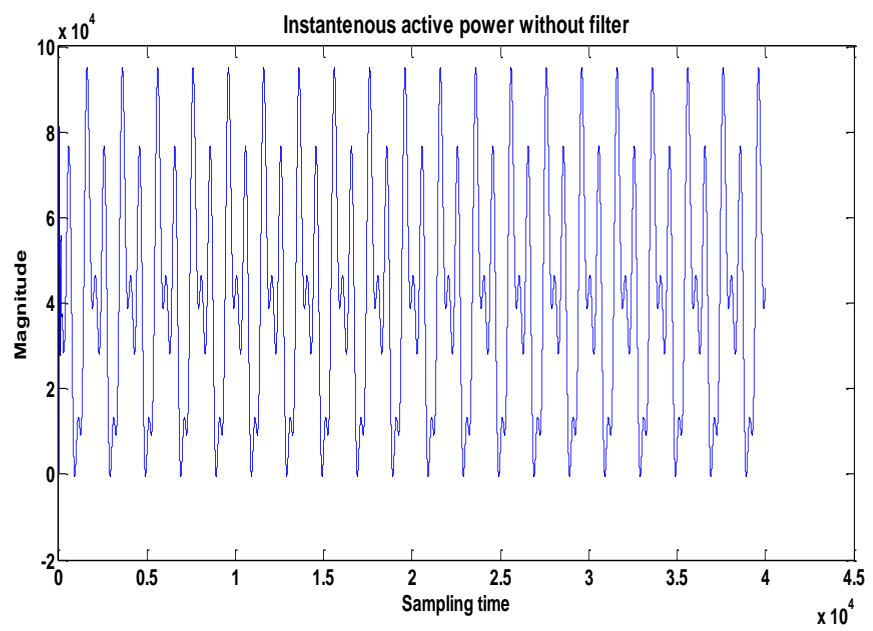
reactive power is shown in fig. 9 when a shunt active power filter is used.
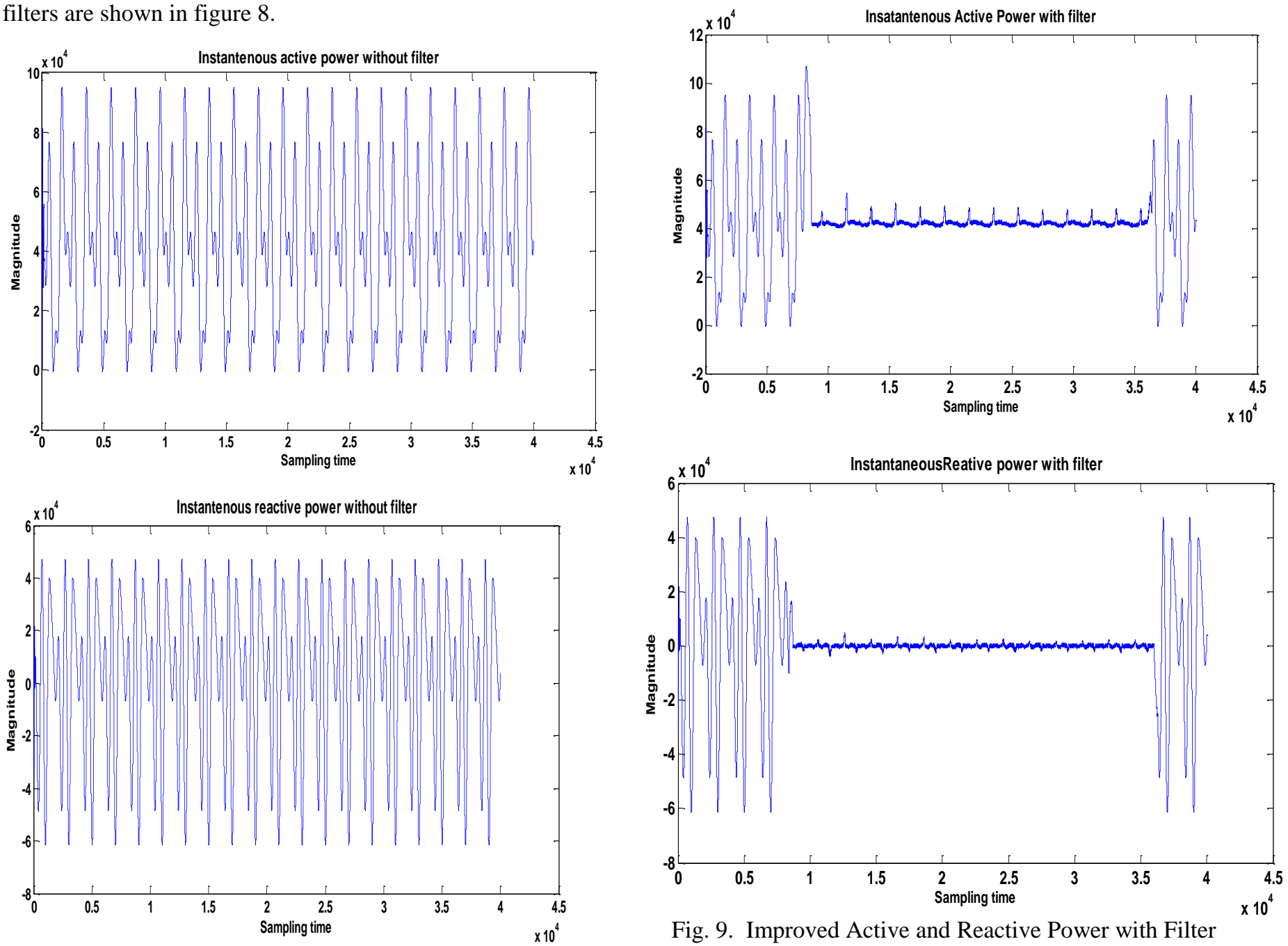

Fig. 8. Active \& Reactive power without Filter

Fig. 9. Improved Active and Reactive Power with Filter
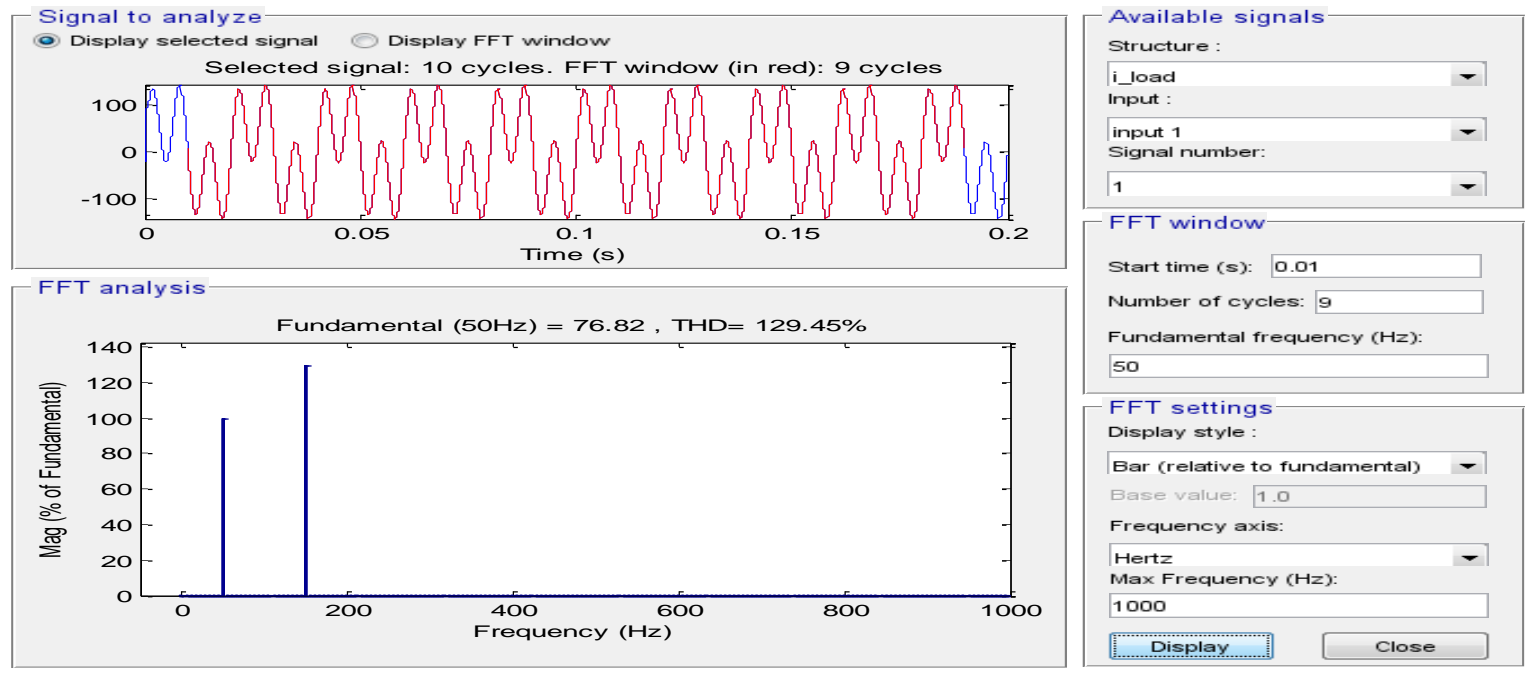
Fig. 10 FFT analysis of \% THD on phase A without Filter
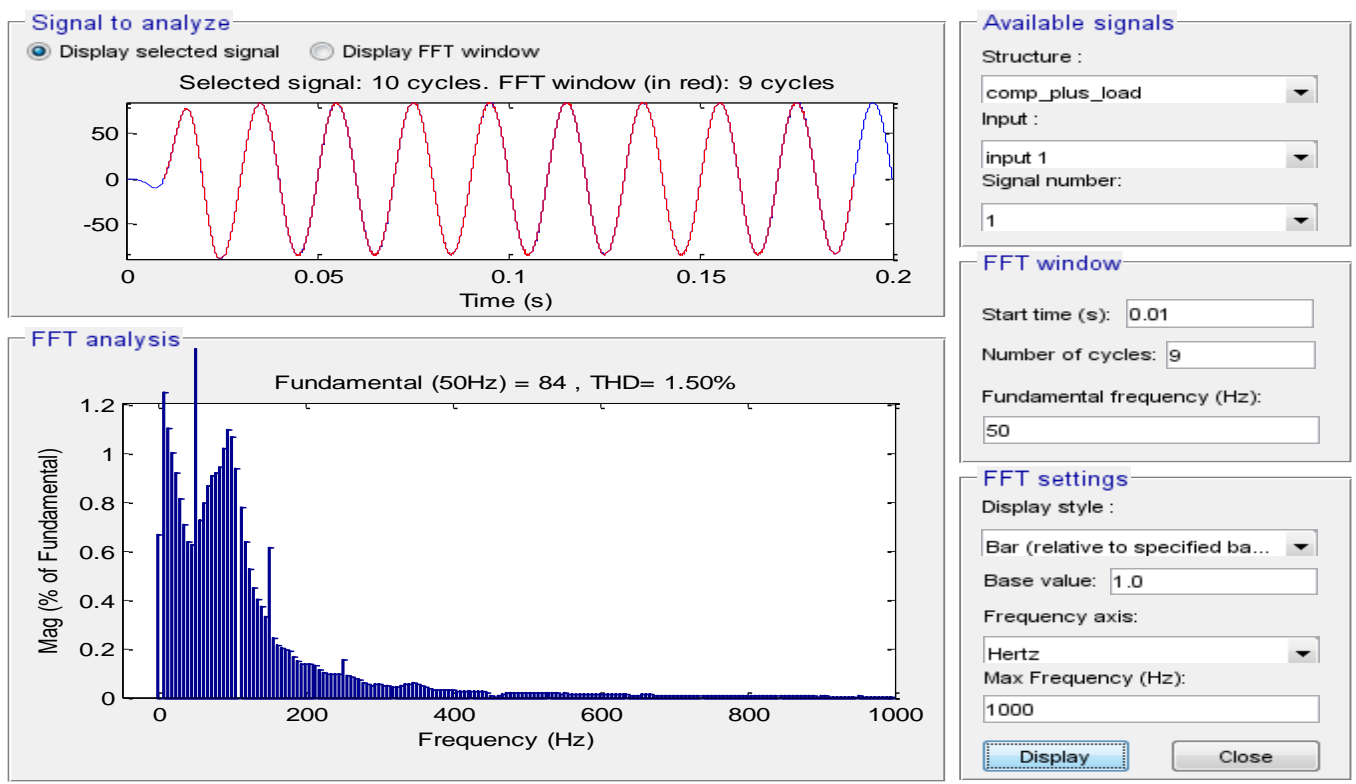

Fig. 11 FFT analysis of \%THD on phase A with Filter

[3] B. Singh, Kamal Al-Haddad, and Ambrish Chandra., "A review of active filters for power quality improvement," EEE transactions on industrial electronics vol. 46, pp. (960-971) 1999.

\section{A. Analysis of FFT \%THD for Harmonics with and Without Filter on Phase A}

It is clear from these figures that THD decreases from $129.46 \%$ to $1.50 \%$ as shown in figs. $10 \& 11$.

\section{CONCLUSION}

Attainment of shunt active power filter investigated on 3$\Phi 400 \mathrm{~V}$ power system with a wind generator acting as a distributed energy source.

I. Instantaneous active power theory in conjunction with Clarke's transformation is found to provide reference harmonic current by choosing disturbance harmonics with more precision \& ease of implementation.

II. Results show that THD has been reduced significantly within the standard recommendation of IEEE-519. We can also observe that the power (active \& reactive) and power factor also be enhanced.

\section{REFERENCES}

[1] Y. Hoon, M. Mohd Radzi, M. Hassan, and N. Mailah, "Control Algorithms of Shunt Active Power Filter for Harmonics Mitigation: A Review," Energies, vol. 10, no. 12, 2017.

[2] K. Poongothai, K. Vijayakumar, and A. Senthilkumar., "Enhancement of Power Quality Using Shunt Active Power filter for Microgrid Application," International Conference on Computation of Power, Energy, Information and Communication (ICCPEIC). IEEE, pp. (0313-0319), 2015.
- Venkataramanan, and Mahesh Illindala, "Microgrids and sensitive loads," IEEE Power Engineering Society Winter Meeting. Conference Proceedings vol. 1, pp. (315-322) 2002.

[5] H. Akagi, E. H. Watanabe, and M. Aredes, Instantaneous power theory and applications to power conditioning. John Wiley \& Sons, 2017.

[6] B. Singh, K. Al-Haddad, and A. J. I. t. o. P. s. Chandra, "A new control approach to three-phase active filter for harmonics and reactive power compensation," vol. 13, no. 1, pp. 133-138, 1998.

[7] G. Laszlo, "Active ac power filters," in IEEE/IAS Anuual Meeting, 1976, pp. 529-535.

[8] T. Toumi, A. Allali, A. Meftouhi, and Abdelkhalek, "Robust control of series active power filters for power quality enhancement in distribution grids: Simulation and experimental validation," vol. 107, pp. 350-359, 2020.

[9] P. Karuppanan and K. K. Mahapatra, "Shunt Active Power Line Conditioners for compensating harmonics and reactive power," in 2010 9th International Conference on Environment and Electrical Engineering, 2010, pp. 277-280: IEEE.

[10] H. Fujita and H. J. I. t. o. p. e. Akagi, "The unified power quality conditioner: the integration of seriesand shunt-active filters," vol. 13, no. 2, pp. 315-322, 1998.

[11] J. Pinto, R. Pregitzer, L. F. Monteiro, C. Couto, and J. L. Afonso, "A combined series active filter and passive filters for harmonics, unbalances and flicker compensation," in 2007 International Conference on 
Power Engineering, Energy and Electrical Drives, 2007, pp. 54-59: IEEE.

[12] M.-S. Nicolae, I.-D. Smarandescu, and A. Tudorascu, "The improvement of power quality in a mono-phase system through a single-phase active filter using MATLAB/simulink," in 2014 International Conference on Applied and Theoretical Electricity (ICATE), 2014, pp. 1-6: IEEE.

[13] S. Saidi, R. Abbassi, S. J. I. J. o. A. C. Chebbi, and S. Processing, "Fuzzy logic controller for three-level shunt active filter compensating harmonics and reactive power," vol. 30, no. 6, pp. 809-823, 2016.

[14] B. I. Chaughule, A. L. Nehete, and R. J. I. J. o. C. E. R. Shinde, "Reduction in harmonic distortion of the system using active power filter in matlab/simulink," vol. 3, no. 6, pp. 59-64, 2013.

[15] O. Ucak, I. Kocabas, and A. J. T.-S. t. r. i. Terciyanli, power electronics, TURKEY, "Design and implementation of a shunt active power filter with reduced dc link voltage," 2008.

[16] A. Farooqi, M. M. Othman, A. F. Abidin, S. I. Sulaiman, M. A. M. J. I. J. o. P. E. Radzi, and D. Systems, "Mitigation of power quality problems using series active filter in a microgrid system," vol. 10, no. 4, p. 2245, 2019.

[17] N. Chellammal, S. S. Dash, V. Velmurugan, and R. Gurram, "Power quality improvement using multilevel inverter as series active filter," in 2012 International Conference on Emerging Trends in Science, Engineering and Technology (INCOSET), 2012, pp. 450-455: IEEE.

[18] J. Wen, L. Zhou, and K. Smedley, "Power quality improvement at medium-voltage grids using hexagram active power filter," in 2010 Twenty-Fifth Annual IEEE Applied Power Electronics Conference and Exposition (APEC), pp. 47-57: IEEE 2010.

[19] Y. A. Garcés Gomez, N. Toro García, F. E. J. J. o. E. Hoyos, and C. Engineering, "New Application's Approach to Unified Power Quality Conditioners for Mitigation of Surge Voltages," vol. 2016, 2016.

[20] R. C. Dugan, M. F. McGranaghan, and H. W. J. N. Y. Beaty, "Electrical power systems quality," 1996.

[21] S. A. Gonzalez, R. Garcia-Retegui, and M. J. I. T. o. I. E. Benedetti, "Harmonic computation technique suitable for active power filters," vol. 54, no. 5, pp. 2791-2796, 2007.

[22] R. Griñó, R. Cardoner, R. Costa-Castelló, and E. J. I. T. o. I. E. Fossas, "Digital repetitive control of a threephase four-wire shunt active filter," vol. 54, no. 3, pp. 1495-1503, 2007.

[23] J. Arrillaga, B. C. Smith, N. R. Watson, and A. R. Wood, Power system harmonic analysis. John Wiley \& Sons, 1997.

[24] R. K. Antar, B. M. Saied, R. A. Khalil, and G. A. Putrus, "HVDC link power quality improvement using a modified active power filter," in 2012 47th International Universities Power Engineering Conference (UPEC), 2012, pp. 1-5: IEEE.

[25] V. S. Kumar, D. Kavitha, K. Kalaiselvi, P. J. J. o. E. E. Kannan, and Technology, "Harmonic mitigation and power factor improvement using fuzzy logic and neural network controlled active power filter," vol. 3 , no. 4, pp. 520-527, 2008.

[26] A. Saleem, J. Zia, M. T. Ahmad, S. U. Khan, S. J. J. o. A. Abbassi, and E. Sciences, "Simulation and Analysis of a Three-phase Shunt Active Power Filter," vol. 10, no. 2, pp. pp 161-165, 2020.

[27] M. Kale and E. Ozdemir, "An adaptive hysteresis band current controller for shunt active power filter\| Electrical power sys," ed: Research, 2005.

[28] M. Kesraoui, A. Chaib, A. Meziane, A. J. E. C. Boulezaz, and Management, "Using a DFIG based wind turbine for grid current harmonics filtering," vol. 78, pp. 968-975, 2014.

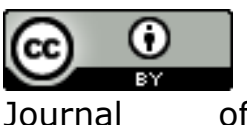

of Applied and Emerging Sciences by BUITEMS is licensed under a Creative Commons Attribution 4.0 International License. 